\title{
GREAT HORNED OWLS OCCUPY ARTIFICIAL NESTING SITE
}

\author{
by Lorne Scott, Indian Head
}

Two Great Horned Owls have nested near the farm at Indian Head for the past several years. Shortly after the young left the nest in 1968, the old dead poplar in which they had nested fell down. After checking the area, I found that there were no other available nesting sites for the owls.

On July 19, 1968, my brother Brian and I decided to place a nest box in some tall poplars near the tree which had fallen down. The box was about two feet square and had sides five inches high. It was placed between two live poplar trees eighteen feet above the ground. We added small sticks and twigs to the box, which we obtained from an old magpie nest.

The sticks and twigs were placed around the sides of the box, thus forming a cup-like depression in the centre of the artificial nest. We added dead leaves to make it look natural, and left it.

When we returned in March 1969, we found the owls were not using our nest, but instead were nesting about one-half mile away in an old crow nest in another dead poplar tree. They successfully raised three young, but again the nest tree fell down later in the season.
We visited the area again in May, and observed a pair of Red-tailed Hawks nearby. I climbed the tree to see if they were nesting, and found they had lined the nest with strips of dead bark and some twigs with green leaves. The nest appeared ready for the laying of eggs. It was a mistake to climb the tree, as the adults abandoned the nest site. Since then I have avoided climbing Red-tailed Hawk nests while they were still building or when there were eggs in the nest.

The site was checked again this past spring on March 22. An adult owl flew off the box when we approached and we discovered three eggs in the nest. They all hatched, and the three young were banded on May 10.

I set up a similar box this past spring in another area, but it was not used this year. We hope to expand this program within the next few years, for perhaps we can increase the number of birds of prey by providing suitable nesting sites for them.

The recent changes to the provincial game act, resulting in complete protection for all birds of prey throughout the year should also benefit these valuable birds.

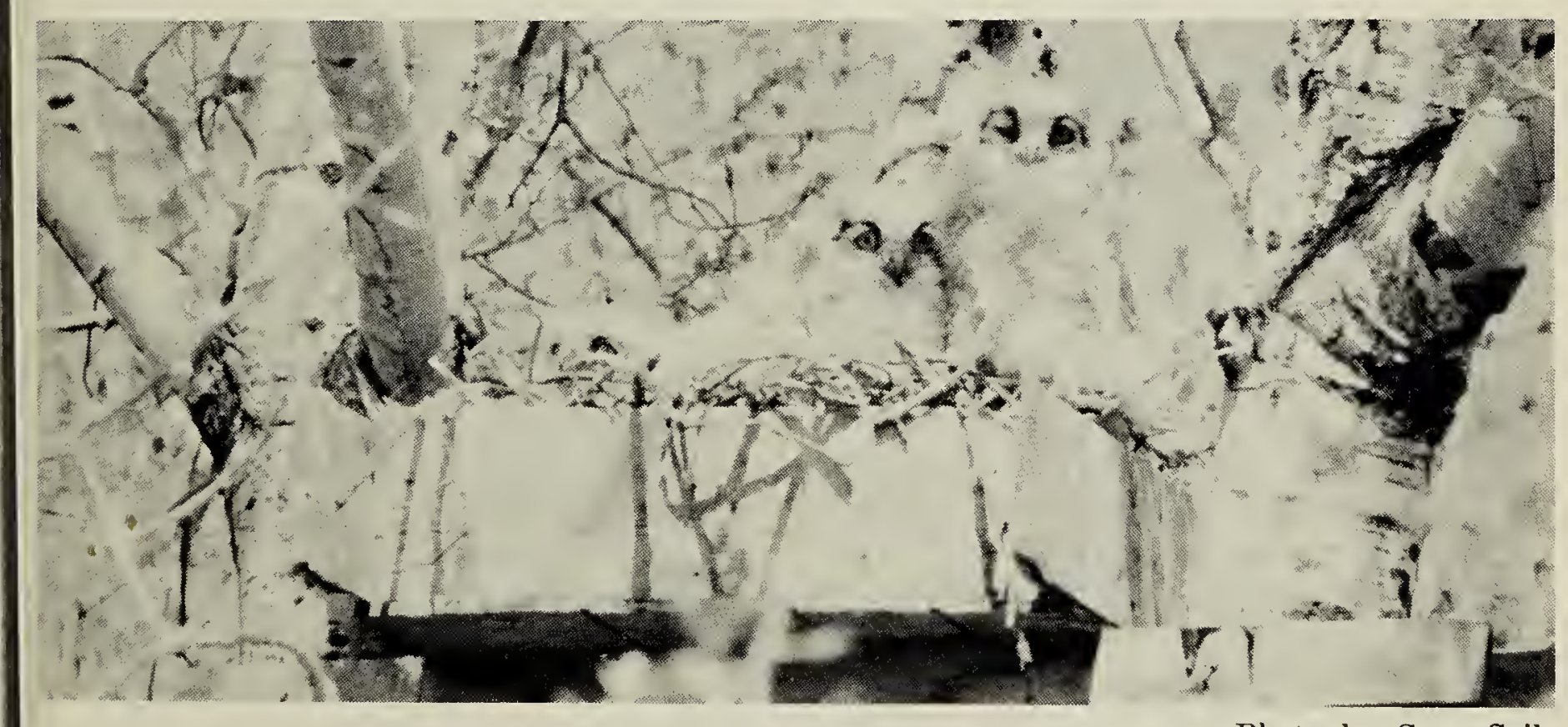

Young Great Horned Owls in artificial nesting site

Photo by Gary Seib 